\title{
Short-term results of the efficacy of percutaneous tibial nerve stimulation on urinary symptoms and its financial cost
}

\author{
(D) Zehra Kurdoğlu1 ${ }^{1}$ (D) Danielle Carr², (D) Jihad Harmouche², (D) Serdar Ünlü2 ${ }^{2}$ (D) Gökhan S. Kılıç2 \\ 1Department of Obstetrics and Gynecology, Ankara Training and Research Hospital, Ankara, Turkey \\ 2Department of Obstetrics and Gynecology, The University of Texas Medical Branch, Texas, USA
}

\section{Abstract}

Objective: Overactive bladder (OAB) affects $16.9 \%$ of women in the United States. Percutaneous tibial nerve stimulation (PTNS) is a thirdline treatment for patients who are refractory to behavioral and pharmacologic therapies. We aimed to evaluate the effects of PTNS on urinary symptoms in patients diagnosed as having refractory OAB and investigate the cost of medications and clinical visits before and after PTNS treatment.

Material and Methods: We reviewed 60 women with refractory OAB treated with PTNS. Episodes of urinary frequency, leakage, urgency, and nocturia; number of follow-up visits; and medications were recorded. The mean quarterly drug, physician, nurse, and provider costs were calculated. The episodes of urinary symptoms, numbers of follow-up visits, and costs of medications and visits before and after PTNS were compared.

Results: Of the 60 patients with refractory OAB, 24 patients who completed 12 weekly sessions of initial PTNS were evaluated. The number of urinary symptoms and follow-up visits significantly decreased after PTNS $(p<0.05)$. The average quarterly medication cost decreased from $\$ 656.36 \pm 292.45$ to $\$ 375.51 \pm 331.79$ after PTNS ( $\mathrm{p}=0.001$ ). After PTNS, quarterly physician and nurse visit costs decreased from $\$ 81.73 \pm 70.39$ to $\$ 25.89 \pm 54.40$ and from $\$ 55.23 \pm 38.32$ to $\$ 15.53 \pm 19.58$, respectively $(\mathrm{p}<0.05)$. The quarterly total provider cost was similar before and after PTNS.

Conclusion: PTNS treatment significantly improved urinary symptoms of patients with refractory OAB and reduced the costs of medications and physician and nurse visits. (J Turk Ger Gynecol Assoc 2018; 19: 7-10)

Keywords: Transcutaneous electric nerve stimulation, tibial nerve, urinary bladder, overactive, costs and cost analysis, lower urinary tract symptoms, office visits

Received: 27 September, 2017 Accepted: 20 December, 2017

\section{Introduction}

Overactive bladder (OAB) syndrome is defined as "urgency, with or without urge incontinence, usually with frequency and nocturia in the absence of proven infection or other obvious pathology" by the International Continence Society (1). The prevalence of $\mathrm{OAB}$ varies between $12.8 \%$ and $17.4 \%$ and increases with age for both sexes $(2,3)$. In the United States (US), its prevalence is $16.0 \%$ in men and $16.9 \%$ in women, and 29.8 million adults aged $\geq 40$ years are estimated to have $\mathrm{OAB}$ symptoms $(4,5)$.
The American Urological Association and the Society of Urodynamics, Female Pelvic Medicine and Urogenital Reconstruction suggest that the first-line treatment should be composed of diet and behavioral therapies such as reducing caffeine, alcohol, and fluid intake; weight loss; pelvic floor physical therapy; timed voiding; and bladder training. Antimuscarinic therapies may be added to behavioral therapies at the same time. Second-line treatment should include pharmacologic agents, antimuscarinics or oral $\beta 3$ adrenoceptor agonists for a minimum of 3 months. Adverse effects of medication or inadequate symptom relief may lead 
to discontinuation of pharmacologic therapy. Intradetrusor botulinum toxin A, percutaneous tibial nerve stimulation (PTNS), and sacral nerve stimulation (SNS) may be recommended as third-line therapies to patients who are refractory to behavioral and pharmacologic therapies (6).

PTNS is the least invasive form of neuromodulation, which uses electrical stimulation to afferent fibers of the posterior tibial nerve (L4-S3) through a needle electrode inserted 3-5 cm cephalad to the medial malleolus. The needle is connected to a device that provides 0.5-9 mA electrical stimulation at $20 \mathrm{~Hz}$. A grounding pad is placed on the bottom of the foot. Nerve stimulation is confirmed by flexion of the big toe and sensory stimulation on the bottom of the foot is created. The exact mechanism of PTNS is unknown. However, it seems that afferent nerve stimulation leads to activation of inhibitory sympathetic neurons through a direct sacral route and modulates the efferent outflow to the lower urinary tract. Treatment is composed of 12 weekly stimulation sessions lasting 30 minutes each. After this initial treatment, sessions may be tapered or maintained according to symptom improvement (7).

The aim of the present study was to evaluate the effects of PTNS on urinary symptoms in patients diagnosed as having refractory $\mathrm{OAB}$ and to analyze the cost of medications and clinical visits before and after PTNS treatment.

\section{Material and Methods}

In this retrospective study, we reviewed patients who were diagnosed as having refractory OAB and treated with PTNS in the Urogynecology Clinic of the University of Texas Medical Branch, a tertiary-care center in Galveston, Texas. Sixty patients who were diagnosed as having $\mathrm{OAB}$ and who were resistant to treatment with anticholinergic medications and behavioral modification participated in this study. Forty-six of the 60 patients had undergone at least 1 PTNS session. Twenty-four had completed 12 weekly PTNS sessions. The weekly stimulation sessions lasted 30 minutes and were performed in an outpatient setting. We included women who were aged 21-85 years, who were diagnosed with refractory $\mathrm{OAB}$, and who had completed 12 weekly PTNS sessions. Pregnant women, those with cancer pacemaker users, Texas Department of Criminal Justice inmates, women who had urinary retention or urinary tract obstruction, and those whose symptoms were suspected to be neurologic or inflammatory in origin were excluded. The study was approved by the Institutional Review Board (IRB: 16-0219).

First, all patients undergoing PTNS treatment were identified using the current procedural terminology code 64566 , which is a medical procedural code under the category - neurostimulator procedures on peripheral nerves. As maintained by the American Medical Association, the procedure was billed under this code, with the descriptor "posterior tibial neurostimulation, percutaneous needle electrode, single treatment, including programming". Then age; body mass index (BMI); episodes of urinary frequency, urgency, nocturia, and incontinence; and numbers of physician and nurse visits were obtained from electronic medical records. Medications used and clinic visits were reviewed within the year before and the year after PTNS treatment. Financial data included the costs of physicians, nurses, and medications. We calculated the costs of visits for physicians and nurses by using plans of Medicare, a US national social insurance program.

Finally, we compared the episodes of urinary symptoms and numbers of follow-up visits and analyzed the difference in the cost of the medications and visits before and after PTNS treatment.

\section{Statistical analysis}

Descriptive statistics for continuous variables are presented as mean \pm standard deviation, and categorical variables are presented as numbers and percentages. We performed statistical analysis by applying the Wilcoxon signed-rank test and paired samples t-test for nonparametric and parametric sample comparison for treatments before and after PTNS, respectively. The results were analyzed with a 95\% confidence interval and $\mathrm{p}<0.05$ was regarded as statistically significant. For the statistical analysis, we used SPSS version 16.0 (SPSS Inc., Chicago, IL, USA).

\section{Results}

A total of 60 patients with a diagnosis of refractory OAB according to the International Continence Society were reviewed. Of the 60 patients, 6 were treated with intradetrusor botulinum toxin A (Botox ${ }^{\circledR}$ ) injection, 7 were treated with SNS, 46 underwent at least 1 PTNS session, and 1 patient declined the third-line treatment. Of the 46 patients, 24 met the inclusion criteria of the study (Figure 1).

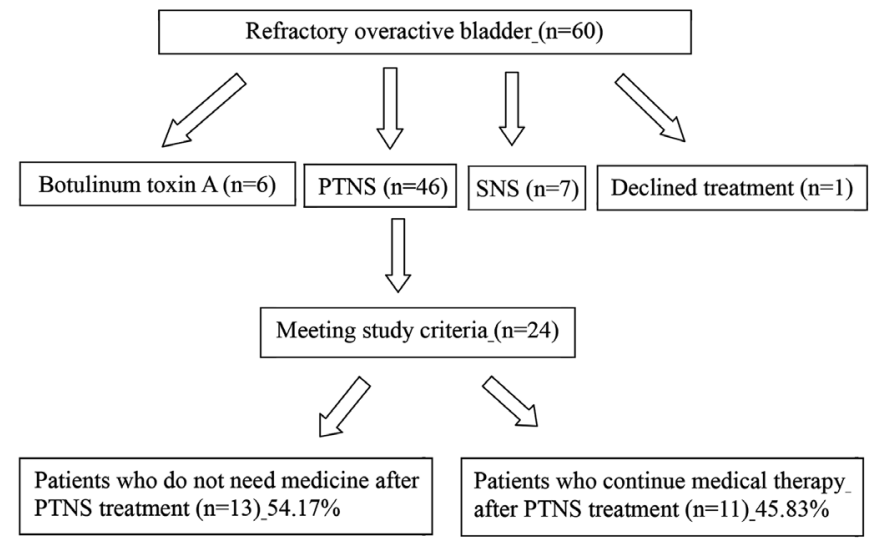

Figure 1. Flow of patients through the trial PTNS: Percutaneous tibial nerve stimulation; SNS: Sacral nerve stimulation 
The mean age of the patients was $70.25 \pm 11.14$ years. The mean BMI was $30.46 \pm 6.86 \mathrm{~kg} / \mathrm{m}^{2}$. After initial PTNS therapy, $54.17 \%$ of the patients required no pharmacotherapy. The number of urgency episodes decreased from 3.12 to $1.79(p=0.001)$, frequency episodes from 7.29 to $5.58(\mathrm{p}=0.002)$, leakage episodes from 2.62 to $1.33(\mathrm{p}=0.002)$, and nocturia episodes from 3.33 to $2.17(\mathrm{p}=0.01)$ (Table 1$)$. The mean number of follow-up visits decreased from $1.34 \pm 0.78$ to $0.40 \pm 0.63$ after PTNS $(\mathrm{p}=0.001)$. After PTNS treatment, quarterly medication, nurse, and physician costs significantly decreased (Table 2). The quarterly total provider cost was calculated by adding the cost of follow-up visits to the cost of PTNS maintenance visits. The quarterly total provider cost was similar before and after PTNS treatment $(\mathrm{p}=0.143)$. However, the total provider cost for the last quarter decreased from $\$ 169.04 \pm 103.69$ to $\$ 55.14 \pm 94.62(\mathrm{p}=0.005)$.

Table 1. Changes in urinary symptom episodes of patients with refractory overactive bladder

\begin{tabular}{|l|l|l|l|}
\hline & Before PTNS* & After PTNS** & p \\
\hline Urgency & $3.12 \pm 1.19$ & $1.79 \pm 1.21$ & 0.001 \\
& $4(1-4)$ & $2(0-4)$ & \\
\hline Frequency & $7.29 \pm 2.15$ & $5.58 \pm 1.90$ & 0.002 \\
& $7(3-12)$ & $5(2-9)$ & \\
\hline Leakage & $2.62 \pm 2.41$ & $1.33 \pm 1.61$ & 0.002 \\
& $2(0-8)$ & $1(0-5)$ & \\
\hline Nocturia & $3.33 \pm 1.81$ & $2.17 \pm 2.06$ & 0.01 \\
& $3(0-7)$ & $2(0-10)$ & \\
\hline
\end{tabular}

PTNS: Percutaneous tibial nerve stimulation; *: At last visit just before PTNS treatment; **: At completion of 12 weekly sessions of initial PTNS treatment

Results are expressed as mean \pm standard deviation, median (minimummaximum)

Table 2. Comparison of quarterly costs before and after percutaneous tibial nerve stimulation treatment

\begin{tabular}{|c|c|c|c|}
\hline & Before PTNS & After PTNS & $\mathbf{p}$ \\
\hline Drug (\$) & $656.36 \pm 292.45$ & $375.51 \pm 331.79$ & 0.001 \\
\hline Physician visit (\$) & $81.73 \pm 70.39$ & $25.89 \pm 54.40$ & 0.004 \\
\hline Nurse visit (\$) & $55.23 \pm 38.32$ & $15.53 \pm 19.58$ & 0.001 \\
\hline Provider (\$) & $136.96 \pm 81.50$ & $181.04 \pm 146.34^{*}$ & 0.143 \\
\hline \multicolumn{4}{|c|}{$\begin{array}{l}\text { PTNS: Percutaneous tibial nerve stimulation; *: With cost of maintenance } \\
\text { PTNS session } \\
\text { Results are expressed as mean } \pm \text { standard deviation }\end{array}$} \\
\hline
\end{tabular}

\section{Discussion}

The results of our study showed that urinary symptoms were improved and the costs of medications and physician and nurse visits were reduced significantly in patients with refractory OAB who were treated with PTNS.
OAB syndrome is composed of symptoms that have significant effects on quality of life. Although urinary frequency, urgency, and nocturia are common symptoms, the main symptom is urgency (8). Patients are in fear of needing to urinate or urinary incontinence. From the patient's perspective, $\mathrm{OAB}$ is a chronic and feared condition due to these symptoms; they feel boxed in and embarrassed (9).

PTNS is a third-line treatment for patients with refractory OAB. This therapy is effective in the alleviation of lower urinary tract symptoms such as incontinence, urgency, and frequency by electrical stimulation to afferent fibers of the posterior tibial nerve to the sacral center of micturition (6). Congregado Ruiz et al. (10) showed that leakage and daytime and nighttime frequency episodes were significantly improved after PTNS treatment (10). van Balken et al. (11) also found a positive response with PTNS therapy in terms of leakage episodes, voiding frequency, and nocturia. The Study of Urgent PC vs Sham Effectiveness in Treatment of Overactive Bladder Symptoms (SUmiT) trial, which was a double-blind, shamcontrolled randomized trial, demonstrated the superiority of PTNS compared with sham groups. It reported moderate or marked improvement in bladder symptoms (54.5\% in the PTNS-treated patients and $20.9 \%$ in the sham group). The study showed that PTNS reduced the number of voids, urgency, and incontinence episodes per day (12). We also found that number of urgency, frequency, leakage, and nocturia episodes significantly improved after PTNS treatment, similar to the literature.

The estimated health care cost of OAB in the USA is more than $\$ 65$ billion per year (13). The total medical cost of patients with $\mathrm{OAB}$ receiving antimuscarinic therapy is estimated to be approximately $\$ 2000$ per year (14). In our study, quarterly drug costs fell by almost half (from $\$ 656.36 \pm 292.45$ to $\$ 375.51 \pm 331.79$ ) after PTNS treatment. We also found a significant reduction in physician and nurse visit costs as a result of the decrease in the number of follow-up visits. Although quarterly total provider costs, including cost of followup visits and PTNS maintenance visits, were statistically similar before and after PTNS $(p=0.143)$, the last quarter cost was significantly decreased from $\$ 169.04 \pm 103.69$ to $\$ 55.14 \pm 94.62$ $(p=0.005)$. We concluded that after the initial 12 weeks of PTNS treatment, diminishing requirements for ongoing therapy towards the end of treatment led to the decrease in the last quarter cost. To the best of knowledge, there are no pure cost analysis studies of PTNS in patients with refractory OAB syndrome in the literature. Staskin et al. (15) reviewed the costs and effectiveness of PTNS in the current treatment of OAB. The authors recommended PTNS as an efficacious, less costly, and less invasive therapy compared with SNS for patients with OAB and refractory to antimuscarinic therapy. Although our study is 
also not an exact cost analysis of PTNS, we noted a reduction in the costs of medications and physician and nurse visits after PTNS treatment.

Our study has some limitations due to its retrospective design. However, the recall bias risk is low because all retrospective data related to the patient treatments and costs were objective data obtained from electronic patient files with no need for recall. Secondly, the size of the study is too small and followup times of the patients are relatively short for the assessment of long-term outcomes of PTNS treatment in patients with refractory $\mathrm{OAB}$. On the other hand, the strength of our study is that it adds new results to the current literature on the changes in urinary symptoms and various costs of PTNS treatment in these patients.

In conclusion, PTNS therapy improves urgency, frequency, nocturia, and leakage episodes in patients with refractory $\mathrm{OAB}$ in the short term. This treatment also reduces the costs of medications and physician and nurse visits in the follow-up of these patients.

Ethics Committee Approval: Ethics committee approval was received for this study from the Ethics Committee of University of Texas Medical Branch (IRB: 16-0219).

Informed Consent: Written informed consent was obtained from patients who participated in this study.

Peer-review: Externally peer-reviewed.

Author Contributions: Concept - Z.K., G.S.K.; Design - Z.K., S. ̈., G.S.K..; Supervision - S.Ü., G.S.K.; Materials - D.C., J.H., Writer - Z.K

Conflict of Interest: No conflict of interest is declared by the authors.

Financial Disclosure: TGGF has provided financial support for this study.

\section{References}

1. Abrams P, Cardozo L, Fall M, Griffiths D, Rosier P, Ulmsten U, et al The standardisation of terminology in lower urinary tract function: report from the standardisation sub-committee of the International Continence Society. Urology 2003; 61: 37-49.
2. Milsom I, Abrams P, Cardozo L, Roberts RG, Thuroff J, Wein AJ. How widespread are the symptoms of an overactive bladder and how are they managed? A population-based prevalence study. BJU Int 2001; 87: 760-6

3. Irwin DE, Milsom I, Hunskaar S, Reilly K, Kopp Z, Herschorn S, et al. Population-based survey of urinary incontinence, overactive bladder, and other lower urinary tract symptoms in five countries: results of the EPIC study. Eur Urol 2006; 50: 1306-14.

4. Coyne KS, Sexton CC, Vats V, Thompson C, Kopp ZS, Milsom I. National community prevalence of overactive bladder in the United States stratified by sex and age. Urology 2011; 77: 1081-7.

5. Stewart WF, Van Rooyen JB, Cundiff GW, Abrams P, Herzog AR, Corey R, et al. Prevalence and burden of overactive bladder in the United States. World J Urol 2003; 20: 327-36.

6. Gormley EA, Lightner DJ, Faraday M, Vasavada SP, American Urological A, Society of Urodynamics FPM. Diagnosis and treatment of overactive bladder (non-neurogenic) in adults: AUA/ SUFU guideline amendment. J Urol 2015; 193: 1572-80.

7. Gupta P, Ehlert MJ, Sirls LT, Peters KM. Percutaneous tibial nerve stimulation and sacral neuromodulation: an update. Curr Urol Rep $2015 ; 16: 4$

8. Osman NI, Chapple CR. Overactive bladder syndrome: Current pathophysiological concepts and therapeutic approaches. Arab J Urol 2013; 11:313-8.

9. Norton C. OAB Evidence from the Patient's Perspective. European Urology Supplements 2003; 2: 16-22.

10. Congregado Ruiz B, Pena Outeiriño XM, Campoy Martínez P, León Dueñas E, Leal López A. Peripheral Afferent Nerve Stimulation for Treatment of Lower Urinary Tract Irritative Symptoms. Eur Urol 2004; 45: 65-9.

11. van Balken MR, Vandoninck V, Gisolf KW, Vergunst H, Kiemeney LA, Debruyne FM, et al. Posterior tibial nerve stimulation as neuromodulative treatment of lower urinary tract dysfunction. J Urol 2001; 166: 914-8.

12. Peters KM, Carrico DJ, Perez-Marrero RA, Khan AU, Wooldridge LS, Davis GL, et al. Randomized Trial of Percutaneous Tibial Nerve Stimulation Versus Sham Efficacy in the Treatment of Overactive Bladder Syndrome: Results From the SUmiT Trial. J Urol 2010; 183: 1438-43.

13. Ganz ML, Smalarz AM, Krupski TL, Anger JT, Hu JC, Wittrup-Jensen $\mathrm{KU}$, et al. Economic Costs of Overactive Bladder in the United States. Urology 2010; 75: 526-32.

14. Hartmann KE, McPheeters ML, Biller DH, Ward RM, McKoy JN, Jerome RN, et al. Treatment of Overactive Bladder in Women. August 2009. In: Evidence Report/Technology Assessment No 187 (Prepared by the Vanderbilt Evidence-based Practice Center under Contract No 290-2007-10065-I) [Internet]. Rockville, MD: Agency for Healthcare Research and Quality: AHRQ Publication No. 09-E017. Available from: http://www.ahrq.gov/downloads/pub/evidence/ pdf/bladder/bladder.pdf.

15. Staskin DR, Peters KM, MacDiarmid S, Shore N, de Groat WC. Percutaneous tibial nerve stimulation: a clinically and cost effective addition to the overactive bladder algorithm of care. Curr Urol Rep 2012; 13 : 327-34 